\title{
Influência Do Perfil Do Dark Triad Dos Acadêmicos Do Curso De Ciências Contábeis Na Qualidade Das Notas Explicativas
}

\section{Influence Of The Dark Triad Profile Of Accounting Sciences Students In The Quality Of Explanatory Notes}

\author{
Bruna Donatelli Armani ${ }^{1}$, Bruna Rodrigues Souza Antunes ${ }^{1}$, Diane Rossi Maximiano Reina ${ }^{1}$, William \\ Aparecido Maciel da Silva ${ }^{2}$, Donizete Reina ${ }^{1}$
}

${ }^{1}$ Universidade Federal do Espírito Santo, UFES, Brasil, ${ }^{2}$ Universidade Federal de Uberlândia, UFU, Brasil.

Correspondência: William Aparecido Maciel da Silva. Av. João Naves de Ávila, 2121, Campus Santa Mônica, Uberlândia, MG, CEP 38400-902. Fonte: +55 (34) 3239-4411. E-mail: w.aparecidomaciel@ hotmail.com.

Recebido: 04 de novembro de 2017 Aceito: 08 de janeiro de 2018 Publicado: 01 de maio de 2018

DOI: http://dx.doi.org/10.21714/1679-18272017v15n2.p576-588

\begin{abstract}
Resumo
O objetivo desta pesquisa é analisar a influência dos traços de personalidade do Dark Triad dos acadêmicos do curso de ciências contábeis na divulgação das informações financeiras apresentadas nas notas explicativas. A amostra utilizada no estudo foi constituída por 100 alunos do curso de ciências contábeis vespertino e noturno do sexto ao oitavo período da Universidade Federal do Espirito Santo (UFES). Em relação aos procedimentos de coleta de dados, foi feita a aplicação do questionário Short Dark Triad (SD3) desenvolvido por Delroy Paulhus e Williams (2002) sobre as três personalidades dessa tríade (psicopatia, narcisismo e maquiavelismo) com a inclusão de perguntas feitas com base no CPC 26 relacionadas as notas explicativas no período de tempo de nove dias contendo um total de 27 questões objetivas e, foi feita uma análise fatorial exploratório. Como principais resultados foram identificados que 14 fatores explicariam mais de $80 \%$ da variância do modelo, enquanto 8 fatores explicariam pouco mais de $61 \%$ se a decisão para tomada de decisão com base na raiz latente (autovalor). Assim, conclui-se que o intervalo de autovalores é que define a utilização de uma maior ou menor quantidade de fatores que consigam explicar o comportamento dos estudantes.
\end{abstract}

Palavras-chave: Dark Triad, Maquiavelismo, Narcisismo.

\begin{abstract}
The objective of this research is to analyze the influence of personality traits of Dark Triad of the accounting sciences students in the disclosure of the financial information presented in the explanatory notes. The sample used in the study consisted of 100 students from the evening and evening accounting courses of the sixth to eighth period of the Federal University of Espirito Santo (UFES). In relation to data collection procedures, the Short Dark Triad (SD3) questionnaire developed by Delroy Paulhus and Williams (2002) was applied to the three personalities of this triad (psychopathy, narcissism and Machiavellianism) with the inclusion of questions asked with based on CPC 26 related to the explanatory notes in the nine-day time period containing a total of 27 objective questions and an exploratory factorial analysis was made. As main results it was identified that 14 factors explained more than $80 \%$ of the variance of the model, while 8 factors would explain little more than $61 \%$ if the decision for decision making based on the latent root (eigenvalue). Thus, it is concluded that the range of eigenvalues is that it defines the use of a greater or lesser amount of factors that can explain the behavior of the students.
\end{abstract}

Keywords: Dark Triad, Machiavellianism, Narcissism.

Esta obra está licenciada sob uma Licença Creative Commons Attribution 3.0.

\section{Introdução}

Tendo Dark Triad como uma teoria que abrange três importantes traços não patológicos da personalidade, sendo elas, a psicopatia, o narcisismo e o maquiavelismo, Paulhus e Willians (2002) constatam no Dark Triad uma série de características relacionadas que implicam em um caráter socialmente malévolo com tendências de 
comportamento para a autopromoção, frieza emocional, duplicidade e agressividade. D'Souza e Lima (2014) definem o Dark Triad como sendo um constructo caracterizado por traços subclínicos de personalidade que mesmo sendo distintos no conceito, possuem características em comum. Lopes et al. (2016) com a intenção de explicar a palavra constructo, por ser pouco utilizada e conhecida, definem como sendo a construção de algo, que teve como início a junção de outros elementos para incrementar uma tese ou teoria.

Especificando os traços que compõem o Dark Triad, tendo como abordagem inicial o maquiavelismo, D'Souza e Lima (2014, p. 5) definiram como sendo "um traço de personalidade pela destreza, manipulação, a utilização de quaisquer meios necessários para atingir um objetivo de natureza política". Jones e Paulhus (2009) associam o maquiavelismo com as características de pessoas manipuladoras e estratégicas e que tem senso ético pragmático e são propensas a usar táticas que visem o alcance de objetivos e ganhos pessoais.

Outra personalidade que compõe a tríade é o narcisismo, definido por D'Souza e Lima (2014) como uma marca de personalidade detectada em indivíduos arrogantes que apresentam um nível superelevado de autoestima, pois acreditam ser especiais e que por isso devem ser louvados e adorados.

Melo Júnior e Ronchi (2013) destacam outra percepção sobre esse traço, sendo ela a frequência significativa de narcisistas ocupando posições de liderança. Isso se dá pelo fato de que pessoas com essa personalidade possuem maior facilidade em controlar situações, fazendo com que consigam, na maioria das vezes de modo antiético, alcançar seu objetivo, no caso referenciado, a liderança. D’Souza (2016, p.24) caracteriza psicopatas como "pessoas oportunistas, egocêntricas, cruéis, cínicas, manipuladoras, ambiciosas e, além disso, ameaçam o desempenho e o alcance do negócio, pois tem em primeiro plano eles próprios, ao invés da empresa" e, a psicopatia é um traço marcado pela manipulação e disposições insensíveis, porém, com enfoque de curto prazo e natureza antissocial.

Diante das considerações iniciais, foi observado que esses traços de personalidade do Dark Triad podem ser encontrados tanto nos profissionais quanto nos acadêmicos de contabilidade (D'SOUZA; LIMA, 2014). Assim foi formulada a questão de pesquisa que norteia esse artigo: Como o comportamento dos acadêmicos do curso de ciências contábeis interfere na qualidade das notas explicativas?

De acordo com as justificativas anteriores, definiu-se como objetivo geral da pesquisa, analisar a influência dos traços de personalidade do Dark Triad dos acadêmicos do curso de ciências contábeis na divulgação das informações financeiras apresentadas nas notas explicativas.

D’Souza (2016) chamou atenção para a importância do estudo dos traços de personalidade do Dark Triad para a contabilidade comportamental, por se tratar de uma temática psicológica e inovadora no contexto nacional, sendo muito importante na utilização desse estudo dentro de uma organização para observar os aspectos positivos e negativos em gestores que possuem essas características psicológicas. D'Souza (2016) ainda afirmou que manipular os resultados para maximizar os ganhos pessoais ou empresariais está associada às características baixas, moderadas e altas dos traços da tríade. Assim, é importante empreender pesquisas que visam entender os distúrbios comportamentais presentes nos gestores que praticam essa ação, nesse caso maquiavelismo, narcisismo e psicopatia. Nesse sentido, a presente pesquisa contribui para o conhecimento geral no âmbito contábil da relação de tais traços comportamentais na qualidade e confiabilidade das informações geradas pelos futuros profissionais da contabilidade.

O artigo está divido em cinco seções, sendo: introdução, fundamentação teórica, a metodologia da pesquisa, descrição e análise dos resultados e considerações finais.

\section{FundamentaçãoT}

\subsection{Dark Triad e Notas Explicativas}

Dark Triad segundo D'Souza (2016) é o termo que relaciona os três traços de personalidade subclínicas (maquiavelismo, psicopatia e narcisismo), que são atributos fundamentados na psicologia social. Black (2013) afirma que esses três traços de personalidade são considerados socialmente aversivos por possuírem características de comportamentos antissocial, manipulação e exploração.

Vale ressaltar que os traços de personalidade Dark Triad não sugerem um diagnóstico clínico de transtornos de personalidade, como é mais estudado a fundo na psicologia ou na psiquiatria, ou seja, não mostram resultados de pessoas que possuem distúrbios mentais clínicos ou que tenham cometidos atos criminais (D'SOUZA; LIMA, 2014), ou que possuam a vulnerabilidade emocional (BLACK, 2013).

Nathanson, Paulhus e Williams (2006), em seu estudo mostraram que estudantes que apresentam os traços do Dark Triad, são candidatos prováveis para se engajar em trapaças escolares. Desta forma, cada um desses três traços de 
personalidades subclínicas serão discutidos mais profundamente, para maior compreensão do Dark Triad.

As notas explicativas "são informações complementares as demonstrações contábeis, representando parte integrante das mesmas" (MARTINS; GELBCKE; SANTOS; IUDICIBUS, 2010, p. 593). Conforme o Pronunciamento Técnico CPC 26, elas devem "prover informação adicional que não tenha sido apresentada nas demonstrações contábeis, mas que seja relevante para sua compreensão".

De acordo com Scharf, Borgert e Paes (2008) a notas explicativas tem o intuito de apresentar informações relevantes, que não podem ser apresentadas nos demonstrativos contábeis, que são de extrema importância para o entendimento da informação contábil. A falta dessas informações prejudica os gestores que precisam das mesmas para uma tomada de decisão. Segundo Campos e Lemes (2013) as notas explicativas auxiliam a evidenciação contábil devido sua principal função ser conceder informações necessárias de forma clara e eficiente importantes para a tomada de decisão.

A publicação das Notas Explicativas está prevista na Lei da Sociedade por Ações $\S 4^{\circ}$ do art. 176 da Lei $n^{\circ}$ 6.404/76, o qual afirma que "as demonstrações serão complementadas por Notas Explicativas e outros quadros analíticos ou demonstrações contábeis necessárias para esclarecimento da situação patrimonial e dos resultados do exercício".

A qualidade das notas explicativas é de extrema importância dentro das demonstrações contábeis, devido a sua relevância para a tomada de decisão. Uma nota explicativa deficiente ou com ausência de evidenciações pode ocasionar em determinações de republicações das demonstrações contábeis (SCHARF; BORGERT; PAES, 2008).

\subsection{Maquiavelismo}

As maiorias das pessoas já conhecem a história do maquiavelismo. Tendo início através de Nicolau Machiavel, que escreveu uma obra sobre o governo da época contando algumas realidades que presenciava por ter sido secretário da segunda Chancelaria no governo de Lourenço Médici. Ficou conhecido por sua coragem, esperteza e até maldade e manipulação, tendo seu nome ligado a essas características e dado origem a um novo conhecimento de personalidade, o maquiavelismo (JONES; PAULHUS, 2009).

Grohmann e Battistella (2012) caracterizam maquiavelismo como "uma estratégia de conduta social, envolvendo manipulação de outras pessoas para a obtenção de ganhos". Jones e Paulhus (2009) relacionam o maquiavelismo com pessoas de caráter manipulador e estratégico que utilizam da ética realista para criar táticas que os fazem alcançar seus objetivos e ganhos pessoais.

\subsection{Psicopatia}

A palavra psicopata está ligada a uma personalidade obscura, em pessoas com um mau-caráter, manipulador, controlador, falso, podendo ser até violento para que consiga chegar onde almeja. Apesar de tantas características distintas, muita das vezes reconhecer um psicopata não é fácil. Ao contrário do que se pensa, o número de pessoas com personalidade psicopata é considerável. D’Souza (2016) em seu estudo que relaciona o Dark Triad com a gestão, faz grandes observações sobre a psicopatia. Ela cita várias características de um psicopata, sendo elas "charme e encanto superficial, impulsividade, vulnerabilidade, ausência de culpa ou remorso, busca de emoções, inteligência, assunção de riscos, baixa empatia, irresponsabilidade, agressividade, falta de consciência, orientação para o presente, imprudência e antissociabilidade" (D'SOUZA, 2016. 25p.).

Ainda sobre o estudo de D'Souza (2016), que liga a psicopatia com a manipulação, aponta que toda e qualquer atividade que precise de um maior contato humano, afasta pessoas com essa personalidade, por estes terem baixa empatia na hora de socializar, sendo emocionalmente frios e objetivos. Sobre o âmbito corporativo, Souza (2016) esclarece que pouco se sabe sobre a psicopatia no meio corporativo e suas implicações e que essa dificuldade advém da ausência de cooperação ativa das organizações dos negócios, especialmente pelas questões éticas e pela dificuldade enfrentada pelos pesquisadores ao tentar desenvolver pesquisas dessa espécie.

No entanto, a colocação de personalidade psicopata de Babiak e Hare (2006) de que esses indivíduos “[...] podem ser surpreendentemente bem-sucedidos ao lidar com os outros (...)são especialistas em analisar as pessoas para depois modificar sua abordagem no intuito de influenciar aqueles que estão em sua volta. ”

No ambiente corporativo Boddy (2011) denominou em seu estudo, como psicopatas corporativos, pessoas que não dão importância a críticas, não se preocupam em criar harmonia entre a equipe de trabalho, acarretando na despensa de bons funcionários, não se importam em investir em negócios arriscados e não se interessam em investir em 'funcionários- talento'. 


\subsection{Narcisismo}

Tendo conhecimento de que o narcisismo teve sua origem ligada a uma lenda, quando Narciso, um homem com grande amor próprio, morreu admirando seu reflexo na água e desde então, teve esse nome associado a uma personalidade aversiva, ligada a pessoas sem modéstia, que passam por cima de outras para se vangloriarem, sempre almejando ser o melhor sem importar-se com as consequências, foram feitos muitos estudos ligando essa personalidade com liderança, desonestidade e outras características. Um desses estudos foi de Avelino e D'Lima (2014) que tentaram associar a personalidade narcisista com a desonestidade no ambiente acadêmico, e através de um questionário passado a alunos de três instituições diferentes, revelaram que, de acordo com sua pesquisa, o gênero masculino é mais propenso a desonestidade que o feminino, porém a relação dessa informação com o narcisismo não foi relevante, chegando a conclusão de que a influência narcisista no âmbito acadêmico não é significativa.

Levando em consideração que a personalidade narcisista já é encontrada em pessoas que fazem parte de grandes organizações, sendo isso comprovado por vários estudos, por apresentarem características como a "autoconfiança, a ambição por poder e a falta de compaixão" (LUBIT, 2002. 1 p.).

Para Vries e Miller (1990), algumas vezes, a eficácia, ou não, da liderança pode ser explicada pela personalidade narcisista do líder, sendo assim, afirmam que de acordo com seu estudo, os líderes costumam ser carismáticos e fazem com que seus 'seguidores' se sintam confiantes e orgulhosos ou, totalmente o contrário, impotentes, dependentes ou até manipuláveis, provocando comportamentos regressivos nos mesmos. É aí que entra a personalidade narcisista, quando o líder consegue a obediência, respeito, dos seus seguidores, usando isso a seu favor no âmbito corporativo, fazendo exigências funcionais em troca de gratificações de caráter narcisista a um líder onipotente.

Já Maccoby (2004) afirma que características do narcisismo podem, de alguma forma, ser benéficas à organização, pois, estas pessoas fazem o que for preciso para conquistar poder e glória, levando assim, ao crescimento da organização. Para isso, usam da inovação e conhecem todas as informações importantes da empresa conseguindo admiração e atingem seus objetivos.

\subsection{Estudos Assemelhados}

Paulhus e Williams (2002) tinham como objetivo de pesquisa dar consistência a teoria de que os perfis maquiavelistas, narcisistas e psicopatas, conhecido como Dark Triad, estariam correlacionados com a personalidade dos estudantes. Para isso, fizeram um questionário e aplicaram aos alunos, obtendo 245 respostas. Analisando-as chegaram ao resultado de que apesar de as medidas se inter-relacionarem, não eram equivalentes.

Outro estudo que leva em conta essa teoria é a tese que relaciona as manobras financeiras com o Dark Triad. D’Souza (2016) analisou os traços de personalidades: maquiavelismo, psicopatia e narcisismo na manipulação de resultados para maximizar ganhos pessoais e empresariais. Foram testadas 3 hipóteses relacionando os perfis que compõem o Dark Triad, e o resultado do estudo confirma a relação entre o narcisismo, maquiavelismo e psicopatia com a decisão de manipular resultados.

Martin et al. (2012) retrataram uma pesquisa com duzentos alunos com o objetivo de investigar as relações entre o estilo Dark Triad (psicopatia, maquiavelismo e narcisismo) e quatro estilos de humor (filiação, auto reforço, agressivo e autodestrutivo). Com o estudo, chegaram ao resultado de que psicopatia e maquiavelismo são relacionados positivamente com o humor agressivo e autodestrutivo, já o narcisismo é correlacionado positivamente com o humor de filiação, mas não com o auto reforço.

Com a ideia de revisar o trabalho de Paulhus e Willians (2002) por já terem muitos outros estudos feitos depois deste, Furnham, Richards e Paulhus (2013) decidiram atualizar e avaliar criticamente o mesmo. Eles comparam as três variáveis que compõem o Dark Triad com medidas de combinações mais recentes. A partir do novo estudo, observaram que os três variáveis principais do Dark Triad ainda são o maquiavelismo, narcisismo e psicopatia.

Comparando uma das variáveis de personalidade do Dark Triad, o narcisismo, com o poder da liderança, Melo Junior e Ronchi (2013) desenvolveram um estudo correlacionando esses dois assuntos. Eles deram enfoque para o narcisismo destrutivo ou reativo e entenderam melhor como essa personalidade está presente dentro das organizações. Com esse estudo eles concluíram que os indivíduos com personalidade narcisista destrutiva ou reativa na maioria das vezes possuem características sádicas, são dominantes, com comportamento agressivo e impõem suas vontades e estão ocupando cada vez mais espaço nas organizações. Por conta dessas características dominantes, narcisistas se sobressaem e chamam atenção, conseguindo assim o poder para liderar.

Ainda sobre o narcisismo, Avelino e Lima (2014) estudaram-no agora dentro do ambiente acadêmico, objetivando 
associar os traços dessa característica com a desonestidade dentro do curso de Ciências Contábeis. Eles aplicaram um questionário para 201 estudantes do curso em 3 instituições diferentes e chegaram ao resultado de que, apesar de a maioria dos alunos terem tendências desonestas para, atingirem suas metas, elas não são relacionadas as características narcisistas, ou seja, chegaram à conclusão de que o narcisismo não influência nas atitudes desonestas dos estudantes de Ciências Contábeis.

Grohmann e Battistella (2012) fizeram uma pesquisa com 320 profissionais dentro de uma organização, para identificar o perfil de personalidade maquiavélica utilizando uma escala de personalidade do maquiavelismo que mede a moralidade, controle, status e descrença, nesses profissionais. Observaram em seus resultados que o desejo por status atingiu o índice mais elevado dessa escala de personalidade, dentre os demais constructos estudados.

D’Souza e Lima (2015) realizaram um estudo para analisar a influência dos três traços não patológicos de personalidade do Dark Triad (narcisismo, psicopatia e maquiavelismo), na tomada de decisões oportunistas. Constataram uma correlação entre altos traços do Dark Triad e a tomada de decisão oportunista, e também foi observado que dependendo do nível desses traços na pessoa (baixo, moderado e alto) também existe uma diferença na tomada de decisão.

\section{Metodologia da Pesquisa}

A presente pesquisa caracteriza-se quanto aos objetivos como um estudo descritivo com abordagem qualitativoquantitativa. Quanto aos procedimentos técnicos, foi realizada uma pesquisa survey. [...] O survey é utilizado como estratégia para responder ao problema de pesquisa e ajudar a identificar a relação entre as variáveis do estudo, especialmente para descrever e comparar comportamentos e atitudes que se diferenciam em função da personalidade (D'SOUZA, 2016, p. 111).

Em relação aos procedimentos de coleta de dados optou-se pela aplicação de um questionário The Dark Side of Accounting de múltipla escolha junto aos estudantes. O estudo de Jones e Paulhus (2014) reforça a ideia da utilização deste questionário, pois segundo os autores os questionários forneceram medidas eficientes, confiáveis e válidas para os traços de personalidade. Assim, para esta pesquisa baseou-se no estudo de Paulhus e Williams (2002), além disso, foi feito uma adaptação do questionário do estudo de Jones e Paulhus (2014). A pesquisa foi efetuada, junto a estudantes de Ciências Contábeis da Universidade Federal do Espirito Santo (UFES) do período vespertino e noturno, matriculados do sexto ao oitavo período, sendo de total sigilo suas identidades. A aplicação do questionário foi efetuada de maneira presencial, pelos autores durante o período de 12 a 21 de junho de 2017.

$\mathrm{O}$ instrumento utilizado consistiu em três partes: (i) informação sobre o perfil do respondente, incluindo informações sobre gênero, idade e exercício de alguma atividade remunerada concomitante ao curso; (ii) questionamento de múltipla escolha contendo 27 questões (sendo 9 sobre maquiavelismo, 9 sobre psicopatia e 9 sobre narcisismo), para verificar a presença destes traços de personalidade comportamental nos devidos estudantes; e (iii) 7 situações desenvolvidas no contexto de uma simulação, utilizando-se como base as normas contábeis de evidenciação das informações em notas explicativas, para que os respondentes possam expressar sua atitude em relação as afirmativas.

Para a primeira e segunda parte do questionário utilizou-se da escala likert e para a terceira parte foram atribuídos valores de 1 a 3 , sendo 1 - Discordo, 2- Neutro e 3-Concordo.

Foi obtido retorno no total 105 questionários respondidos. Desses, 6 foram descartados por serem classificados como inválidos, pelo não preenchimento total do mesmo ou pela marcação de uma única alternativa para todas as perguntas, não podendo ser usado como amostra para não comprometer a validação do resultado da pesquisa. Dessa forma, a amostra final foi de 99 questionários integralmente respondidos e que puderam ser utilizados na pesquisa.

Para mensurar o nível de cada um dos traços de personalidade de forma individual, foi feita uma média aritmética para as nove afirmativas referentes a cada traço da personalidade (maquiavelismo, narcisismo e psicopatia) para cada participante da pesquisa, utilizando como base a equação abaixo.

$$
S=\frac{\sum X_{i}}{N}
$$

Onde:

$\mathrm{S}=$ Nível de influência da subclasse na personalidade.

$\mathrm{X}_{\mathrm{i}}=$ Valor atribuído a resposta, de acordo com escala likert.

$\mathrm{N}=$ Número de observações. 
Este cálculo quando aplicado as 9 questões referentes um dos traços de personalidade em estudo resultaram na influência do mesmo dentro da personalidade do indivíduo respondente. Os resultados possíveis para este cálculo estão compreendidos em um intervalo de 1 a 5 , no qual zero é tido como valor mínimo e quatro como máximo.

Desta forma, foi possível estimar quais alternativas têm sido a mais selecionada para cada uma das 27 afirmativas propostas e assim avaliar o nível de cada um dos componentes da Triad baseando-se no percentual de escolhas que mais se repetiram. Por fim, destaca-se que quanto ao nível deste constructo os alunos podem ser considerados mediano, por apresentarem um baixo valor de psicopatia e um valor mediano para o narcisismo e maquiavelismo (SILVA et al., 2016).

\section{Análise dos Resultados}

Para a análise dos resultados foram estabelecidos níveis de classificação para os traços de personalidade em estudo. Para tanto, foi calculado o tercil, dividindo o intervalo da amostra em três partes: baixo, moderado e alto. Determinou-se os intervalos de cada seção utilizando como base os valores máximos e mínimos identificados dentro da amostra, para cada um dos traços de personalidade (maquiavelismo, narcisismo e psicopatia), em seguida calculou-se a amplitude de cada nível e, por fim, os intervalos. Os intervalos foram calculados através do quociente entre os valores das amplitudes e o número de níveis estabelecidos.

Tabela 1: Níveis de classificação dos traços de personalidade

\begin{tabular}{|l|c|c|c|}
\hline \multicolumn{1}{|c|}{ Nível } & Maquiavelismo & Narcisismo & Psicopatia \\
\hline Baixo & 1,22 a 2,26 & 2,11 a 2,81 & 1,22 a 2,07 \\
\hline Moderado & 2,27 a 3,31 & 2,82 a 3,52 & 2,08 a 2,93 \\
\hline Alto & 3,32 a 4,33 & 3,53 a 4,22 & 2,94 a 3,78 \\
\hline
\end{tabular}

Fonte: Elaborado pelos autores.

Na sequência apresentam-se a avaliação dos traços de personalidade dos respondentes, de forma unitária e geral.

Ao analisar os dados de forma individual dos respondentes no que tange ao maquiavelismo, observou-se que segundo o nível de classificação dos traços de personalidade $69,2 \%$ dos investigados apresentam traços moderado de maquiavelismo; $35 \%$ dos participantes assinalaram que concordam ou concordam totalmente com a assertiva "gosto de usar a manipulação inteligente para fazer do meu jeito", $25 \%$ responderam que fazem o que for preciso para ter pessoas importantes ao seu lado, $10 \%$ dos participantes concordam com a assertiva "certifico-me que os planos me beneficiem, e não aos outros", e 59,6\% afirmam que a maioria das pessoas podem ser manipuladas. Tais resultados corroboram com os achados de Silva et al. (2016), quanto aos traços moderado de maquiavelismo, entretanto, apresentam percentuais menores: $40,7 \%$ em relação a assertivo "gosto de usar a manipulação inteligente para fazer do meu jeito"; $30,83 \%$ afirmam fazer o que for preciso para ter pessoas importantes ao seu lado; e, 20,15\% dos participantes concordam com a assertiva "certifico-me que os planos me beneficiem, e não aos outros".

Constatou-se que de forma geral, a influência do maquiavelismo na personalidade da amostra investigada, com base nas respostas que mais se repetiram para cada assertiva é de 3,0. Representando, um nível moderado de maquiavelismo, esse resultado corrobora com os achados de Silva et al. (2016).

No que concerne aos traços de narcisismo, $86,2 \%$ dos investigados possuem traços moderado de narcisismo, em geral o nível influência do narcisismo na personalidade dos respondentes também é moderado cujo valor 3, bem próximo ao limite superior do nível moderado. Os resultados encontrados são superiores aos de Silva et al. (2016), onde $66 \%$ da amostra possui traços moderados de narcisismo e quanto a influência do narcisismo na personalidade dos respondentes o valor foi próximo ao limite inferior do nível moderado.

Em relação às respostas individuais constataram-se que: $7 \%$ das pessoas que concordaram com a afirmativa de "odeio ser o centro das atenções" também concordam que "muitas das atividades em grupo tendem a ser maçantes sem mim", $62 \%$ dos respondentes insistem em obter o respeito que merecem; e, $68 \%$ dos respondentes discordam ou discordam totalmente com a afirmativa "eu sou uma pessoa mediana". Essas características, corroboram com as mencionadas por Paulhus e Williams (2002) ao observar que indivíduos narcisistas exibem traços comportamentais de grandiosidade, necessidade de dominação e sentimento de superioridade.

Os indivíduos com traços de psicopata possuem características comportamentais como egoísmo, oportunismo, enganação, ausência de culpa, ou seja, os psicopatas tendem a quebrar regras, sem se preocupar com a culpa ou remorso (D’SOUZA, 2016; SILVA et al., 2016).

Quanto aos dados individuais em relação à psicopática constatou-se que $23,3 \%$ dos respondentes acreditam que 
podem ser mais com os outros, $58 \%$ nunca entraram em conflito com a lei; $7 \%$ dos respondentes concordaram ou concordaram parcialmente com a assertiva "digo qualquer coisa para conseguir o que quero". As informações evidenciadas nessa pesquisa são inferiores aos percentuais encontrados por Silva et al. (2016).

Em geral observa-se que geral 52,4\% dos respondentes apresentam nível moderado de personalidade em relação à psicopatia. Contrariando os achados de Silva et al. (2016) que encontrou traços de personalidade em nível baixo de psicopatia.

Quanto às questões relacionadas à divulgação das notas explicativas: (i) - 76\% dos alunos discordam com a afirmativa "A empresa possui um passivo contingente pela utilização de uma substancia em seus produtos que podem trazer riscos à saúde dos consumidores, por se tratar de valores ainda não definidos quanto a sua exigibilidade deve-se proceder a divulgação de tal fato nas notas explicativas. Entretanto, o gestor solicita que tais informações não sejam divulgadas devido ao seu impacto negativo para com a empresa. Em busca de sua valorização profissional, tal informação não foi divulgada"; (ii) - 74,5\% dos alunos concordam que em relação aos ativos intangíveis deve-se divulgar os prazos de vida útil bem como os métodos de amortização; (iii) - 71,6\% dos alunos discordam com a assertiva "Ao revisar os saldos iniciais da conta de depreciação acumulada observou-se que no ano de 2015 não foi incluso no cálculo a depreciação de um imóvel novo adquirido pela empresa. Tal erro deve ser objeto de ajuste na elaboração da Demonstração das Mutações do Patrimônio Líquido (DMPL), bem como a menção em nota explicativa. Entretanto, por estar prestes a ganhar uma promoção, em sua percepção tal erro pode denegrir sua imagem profissional, não sendo, portanto, tal informação objeto de ajuste e menção em nota explicativa"; (iv) - 73,5\% discordam que ao mencionar uma informação obrigatória na nota explicativa que impacta negativamente no desempenho econômico e financeiro da empresa. Apresentaria informação em demasia como forma a dissuadir/ e ou confundir o usuário em seu processo de tomada de decisão; (v) - 55,9\% dos respondentes discordam com a afirmativa "A empresa possui financiamento cujo imóvel objeto do financiamento foi dado em garantia. Ao elaborar a nota explicativa essa informação foi mencionada bem como o valor do ativo dado em garantia"; e (vi) - 73,5\% dos que concordam que as informações evidenciadas nas notas explicativas foram elaboradas seguindo as normas estabelecidas nos pronunciamentos contábeis.

De acordo com Tabela 2 pode-se observar que alguns fatores como P4; P15; e P20 tiveram uma média alta entre seus respondentes.

Tabela 2: Estatística descritiva

\begin{tabular}{|l|r|r|r|}
\hline & Média & Desv. Padrão & Questões Analisadas \\
\hline P1 & 2,81 & 1,047 & 99 \\
P2 & 3,03 &, 963 & 99 \\
P3 & 2,62 & 1,122 & 99 \\
P4 & 3,47 & 1,063 & 99 \\
P5 & 2,88 & 1,100 & 99 \\
P6 & 2,29 & 1,154 & 99 \\
P7 & 3,32 & 1,132 & 99 \\
P8 & 2,30 &, 897 & 99 \\
P9 & 3,53 & 1,063 & 99 \\
P10 & 2,89 & 1,096 & 99 \\
P11 & 3,37 & 1,139 & 99 \\
P12 & 2,63 & 1,036 & 99 \\
P13 & 2,61 &, 956 & 99 \\
P14 & 3,55 & 1,003 & 99 \\
P15 & 3,70 & 1,165 & 99 \\
P16 & 2,11 &, 989 & 99 \\
P17 & 3,00 & 1,107 & 99 \\
P18 & 3,65 &, 993 & 99 \\
\hline
\end{tabular}




\begin{tabular}{|c|c|c|c|}
\hline P19 & 1,96 & ,936 & 99 \\
\hline P20 & 3,71 & 1,062 & 99 \\
\hline P21 & 1,96 & ,844 & 99 \\
\hline P22 & 2,18 & 1,110 & 99 \\
\hline P23 & 2,43 & 1,239 & 99 \\
\hline P24 & 2,21 & 1,109 & 99 \\
\hline P25 & 3,56 & 1,239 & 99 \\
\hline P26 & 1,92 & 1,192 & 99 \\
\hline P27 & 1,90 & |964, & 99 \\
\hline
\end{tabular}

Fonte: Elaborado pelos autores.

A matriz de correlação de Pearson pode-se observar que na parte de cima da matriz existem várias correlações entre os fatores analisados nos três níveis, maquiavelismo, narcisismo e psicopatia. A matriz identificou várias correlações entre os 27 fatores analisados.

Nesse estudo, o teste de Bartlett's que mede o grau de ajuste a análise fatorial está acima de 0,5 , ou seja, o teste está adequado aos resultados. Observa-se também, conforme Tabela 2 que o nível de significância deu próximo de zero validando assim o grau de ajuste, já que quanto mais próximo de zero for a significância na análise fatorial mais adequado é o teste.

Tabela 3: Teste de esfericidade - KMO e Teste Bartlett's

\begin{tabular}{|c|c|c|}
\hline \multicolumn{2}{|c|}{ Kaiser-Meyer-Olkin Measure of Sampling Adequacy. } & ,642 \\
\hline & Approx. Chi-Square & 779,310 \\
\hline \multirow[t]{2}{*}{ Bartlett's Test of Sphericity } & $\mathrm{df}$ & 351 \\
\hline & Sig. & ,000 \\
\hline
\end{tabular}

Fonte: Elaborado pelos autores.

Outro teste realizado foi com relação às cumunalidades. A cumunalidade revela as correlações entre as variáveis e o quanto a variância e as variáveis podem explicar os fatores analisados. Ou seja, as cumunalidade medem o poder de explicação das variáveis e, quanto maior esse valor maior é o poder de explicação. É considerado um poder de explicação aceitável quando esse valor está acima de 0,5 . Assim, abaixo de 0,5 o poder de explicação é considerado baixo, ou pobre. Conforme a Tabela 4 , todas ás variáveis analisadas possuem podem de explicação acima de 0,5 , isto é, aceitável.

Tabela 4: Correlação das variáveis - comunalidades

\begin{tabular}{|l|r|r|}
\hline & Inicial & Extração \\
\hline P1 & 1,000 &, 598 \\
P2 & 1,000 &, 575 \\
P3 & 1,000 & \\
P4 & 1,000 &, 546 \\
P5 & 1,000 &, 666 \\
P6 & 1,000 &, 655 \\
P7 & 1,000 &, 675 \\
P8 & 1,000 &, 685 \\
P9 & 1,000 &, 617 \\
p10 & 1,000 &, 606 \\
p11 & 1,000 &, 637 \\
p12 & 1,000 &, 532 \\
p13 & 1,000 &, 530 \\
& &, 596
\end{tabular}




\begin{tabular}{|l|l|} 
p14 & 1,000 \\
p15 & 1,000 \\
p16 & 1,000 \\
p17 &, 604 \\
p18 &, 592 \\
p19 &, 600 \\
p20 & 1,000 \\
p21 & 1,000 \\
p22 & 1,000 \\
p23 &, 563 \\
p24 &, 696 \\
p25 &, 548 \\
p26 & 1,000 \\
p27 & 1,000 \\
1,000 &, 621 \\
\hline
\end{tabular}

Fonte: Elaborado pelos autores.

A forma de extração adotada para identificar quais as variáveis apresentam maior poder de explicação foi método dos componentes principais. Esse método é recomendado pela literatura em função de identificar quais os eixos principais representam melhor os resultados. Foi possível verificar que $61 \%$ dos fatores analisados podem ser explicados por apenas 8 fatores, mesmo após os ajustes das cargas fatoriais.

$\mathrm{Na}$ Tabela 5 são apresentadas as cargas fatoriais, ou seja, a carga que cada fator da matriz componente possui quando do início da análise fatorial. Observa-se que o modelo apresenta nas colunas componentes apenas os 8 fatores que conseguem explicar os mais de $60 \%$ da variância identificados inicialmente. Assim, cada um dos 8 fatores é capaz de explicar um percentual de variância dos $100 \%$ dos fatores.

Tabela 5: Componentes da matriz - cargas fatoriais

\begin{tabular}{|c|c|c|c|c|c|c|c|c|}
\hline & \multicolumn{8}{|c|}{ Componentes } \\
\hline & 1 & 2 & 3 & 4 & 5 & 6 & 7 & 8 \\
\hline P1 & ,254 &,- 090 & ,024 &,- 434 &,- 071 &,- 439 & ,309 &,- 207 \\
\hline P2 & ,387 & ,444 & , 130 & 019 & ,310 &,- 173 & ,078 &,- 279 \\
\hline P3 & ,513 & ,405 &,- 034 & -002 &,- 319 &,- 046 & , 107 & ,039 \\
\hline P4 & ,111 & 239 & ,577, & ,405 & -299 & 029 &,- 029 &,- 092 \\
\hline P5 & ,457 & ,418 & , 124 &,- 025 & 249 &,- 379 &,- 202 & ,098 \\
\hline P6 & ,645 & ,312 &, 127 &,- 009 &,- 103 &,- 284 &,- 229 &,- 037 \\
\hline P7 & ,373 & ,482 & ,023 & -148 &,- 118 & ,320 & ,098 &,- 406 \\
\hline P8 & ,558 & ,255 & ,145 & ,088 &, 074 & ,299 &,- 303 & ,158 \\
\hline P9 & 395 & ,210 & ,317 &,- 104 & ,510 & , 156 & ,080 &,- 059 \\
\hline p10 & ,377 & ,096 &,- 626 &, 110 & ,213 & , 189 &,- 001 &,- 022 \\
\hline p11 &,- 376 &,- 064 & ,464 & 221 & ,087 & ,076 & ,162 & 287 \\
\hline p12 & ,322 & ,046 &,- 110 &,- 016 & ,113 & ,475 & ,348 & ,228 \\
\hline p13 & ,434 &,- 128 &,- 136 & ,472 & ,061 & ,006 & ,321 & -208 \\
\hline p14 & ,158 &, 007 &,- 127 & ,696 & ,083 & , 102 &,- 160 &,- 190 \\
\hline p15 &,- 267 &,- 091 & ,191 &, 135 & ,242 &,- 196 &, 559 &,- 220 \\
\hline p16 & ,348 &,- 031 &,- 266 & ,275 & ,467 &,- 081 & ,268 & ,241 \\
\hline p17 &,- 293 & 039, & ,486 & ,370 &,- 201 &, 010 & ,245 & ,049 \\
\hline
\end{tabular}




\begin{tabular}{|c|c|c|c|c|c|c|c|c|}
\hline p18 & ,355 & ,250| &,- 128 & ,249| &,- 165 &,- 313 &,- 037 & ,550 \\
\hline p19 & ,599 &,- 136 & ,235 &,- 038 & ,194 &,- 262 &, 010 & 085 \\
\hline p20 &,- 261 & ,635 &,- 123 &,- 179 &,- 088 &, 157 & 249 & ,092 \\
\hline p21 & ,636 &,- 311 &,- 016 & ,002 &,- 171 & ,113 & ,211 & ,090 \\
\hline p22 & ,546 &,- 453 &,- 065 & ,077, &,- 055 &,- 038 &,- 177 & -277, \\
\hline p23 & 612, &,- 308 & ,345 &,- 224 &,- 096 & ,059 & ,160 & \\
\hline p24 & |591, &,- 351 &,- 169 &,- 114 &,- 292 &,- 076 & ,274 & 167 \\
\hline p25 &,- 268 & ,631 &,- 129 &,- 145 &,- 096 &,- 009 & ,267 & ,093 \\
\hline p26 &, 115 &,- 197 & ,394 &,- 356 & ,436 & 298 &,- 142 & ,13 \\
\hline p27 & 602 &,- 020 & ,137 &,- 075 &,- 363 & ,334 & ,011 &,- 0 \\
\hline
\end{tabular}

Fonte: Elaborado pelos autores.

$\mathrm{Na}$ Tabela 6 é possível observar a rotação realizada nas cargas dos fatores como base nos componentes principais e adotando a rotação ortogonal. Como o objetivo nessa pesquisa é reduzir a quantidade de fatores que expliquem um maior percentual das características comportamentais dos estudantes que se dividem entre narcisismo, maquiavelismo e psicopatia. Desta forma, a rotação das cargas conforme a matriz ortogonal apresentada abaixo busca mostrar como fica a posição dos fatores após essa primeira rotação ortogonal. A rotação ortogonal rotacional os eixos de forma perpendicular entre si, ou seja, em torno de $90^{\circ}$ graus. E, esses fatores são rotacionais nos 4 quadrantes sempre em relação aos $90^{\circ}$.

Tabela 6: Matriz Ortogonal usada na rotação dos fatores

\begin{tabular}{|c|c|c|c|c|c|c|c|c|}
\hline & \multicolumn{8}{|c|}{ Componentes } \\
\hline & 1 & 2 & 3 & 4 & 5 & 6 & 7 & 8 \\
\hline $\mathrm{P} 1$ & ,313 & ,254 &,- 043 &,- 210 &,- 244 &,- 058 & ,069 &,- 568 \\
\hline $\mathrm{P} 2$ &,- 077 &, 585 &, 087 &,- 027 & ,221 & ,183 & ,319 &,- 186 \\
\hline P3 & ,407 & ,443 & 243 &,- 002 & ,071 &,- 200 &, 247 & ,139 \\
\hline P4 &, 046 & ,249 &,- 053 & ,706 &, 012 &,- 094 &, 257 & 157 \\
\hline P5 &,- 035 & ,791 & ,029 &,- 083 &, 038 & ,118 &,- 041 &, 052 \\
\hline P6 & ,233 & ,736 &,- 113 &,- 043 &,- 027 &,- 078 & , 184 &, 151 \\
\hline P7 &, 167 & ,219 & ,255 &,- 071 & ,074 & ,081 &, 722 & ,072 \\
\hline P8 & ,207 & ,391 &,- 041 & ,011 & ,149 & ,283 &, 184 &, 532 \\
\hline P9 &, 048 &, 364 &, 022 & ,020 &, 188 & ,628 & ,193 &,- 058 \\
\hline $\mathrm{p} 10$ &, 100 & ,059 & ,059 &,- 549 &, 520 &,- 036 & ,094 & ,193 \\
\hline p11 &,- 130 &,- 193 & ,097 &, 576 &,- 021 &, 217 &,- 296 &,- 033 \\
\hline p12 &, 426 &,- 130 & ,269 &,- 083 &, 354 &, 322 & ,059 & , 139 \\
\hline p13 & ,269 &, 087 &,- 215 &, 061 & ,638 &,- 121 &, 148 &,- 150 \\
\hline p14 &,- 182 &, 058 &,- 285 &, 153 &, 587 &,- 196 &, 135 & ,249 \\
\hline p15 &,- 127 &,- 137 &, 065 & ,283 & 209 & ,082 &,- 038 &,- 649 \\
\hline p16 &, 131 & 201 & 017 &,- 190 & ,627 &, 177 &,- 308 &,- 095 \\
\hline p17 &,- 047 &,- 124 &, 085 & ,722 &, 020 &,- 076 &,- 037 &,- 094 \\
\hline $\mathrm{p} 18$ & ,268 & ,488 & ,178 & ,038 &, 172 &,- 277 &,- 413 & ,277 \\
\hline p19 &, 344 & ,494 &,- 313 &,- 013 & ,076 & 240 &,- 105 &,- 113 \\
\hline p20 &,- 121 &,- 003 & ,760 &,- 007 &,- 054 &,- 040 &, 155 & 019 \\
\hline p21 &, 701 &, 067 &,- 236 &,- 067 & ,189 & ,046 &, 044 & 029 \\
\hline p22 &, 326 & , 102 &,- 647 &,- 196 & ,132 &,- 052 & ,179 &, 021 \\
\hline
\end{tabular}




\begin{tabular}{|c|c|c|c|c|c|c|c|c|}
\hline p23 & ,688 &, 180 &,- 267 & ,079 &,- 102 & ,304 &, 035 &,- 053 \\
\hline $\mathrm{p} 24$ & ,772 &, 064 &,- 173 &,- 196 &, 084 &,- 136 &,- 095 &,- 078 \\
\hline $\mathrm{p} 25$ &,- 145 & ,079 &, 733 &, 006 &,- 057 &,- 129 & ,082 &,- 070 \\
\hline p26 &, 047 &,- 022 &,- 163 &,- 019 &,- 199 & ,758 &,- 045 & ,079 \\
\hline p27 & ,610 &, 108 &,- 109 &, 046 &,- 010 &, 048 & ,400 & ,272 \\
\hline
\end{tabular}

Fonte: Elaborado pelos Autores.

Após a rotação dos componentes principais pelo método de rotação varimax, observa-se que quando os componentes são rotacionados em relação ao ângulo de $90^{\circ}$ graus eles assumem novas posições dentro do quadrante.

Tabela 7: Matriz com os scores de coeficientes

\begin{tabular}{|c|c|c|c|c|c|c|c|c|}
\hline & \multicolumn{8}{|c|}{ Componentes } \\
\hline & 1 & 2 & 3 & 4 & 5 & 6 & 7 & 8 \\
\hline $\mathrm{P} 1$ & ,110 & ,120 & ,004 &,- 101 &,- 162 &,- 082 & ,051 &,- 425 \\
\hline $\mathrm{P} 2$ &,- 147 & ,222 &, 004 &,- 008 &, 097 & ,079 & , 182 &,- 199 \\
\hline P3 &, 148 &, 107 & ,149 & ,043 &,- 019 &,- 150 & 070 & ,033 \\
\hline $\mathrm{P} 4$ &, 008 &, 086 &,- 055 & ,389 &, 001 &,- 088 &, 150 &, 078 \\
\hline P5 &,- 130 & ,359 &,- 006 &,- 033 &,- 042 & ,038 &,- 132 &,- 006 \\
\hline P6 &,- 029 & ,285 &,- 067 &, 007 &,- 103 &,- 102 & ,031 &, 042 \\
\hline P7 & ,011 &,- 032 &, 096 &,- 025 &, 015 &, 030 &, 477 &,- 030 \\
\hline P8 &,- 007 &, 072 &, 001 & ,034 &, 021 & , 158 &, 024 &, 338 \\
\hline P9 &,- 069 & ,092 &, 028 & ,018 & ,093 &, 365 &, 083 &,- 071 \\
\hline $\mathrm{p} 10$ &,- 032 &,- 060 & ,053 &,- 263 & ,258 &,- 005 &, 035 & ,092 \\
\hline p11 &, 046 &,- 037 & ,072 & ,295 &, 047 &, 153 &,- 206 &, 028 \\
\hline p12 & ,218 &,- 189 & ,236 &,- 003 & ,198 & ,216 &,- 025 &, 084 \\
\hline p13 & ,044 &,- 042 &,- 066 &, 081 &, 345 &,- 095 & ,108 &,- 165 \\
\hline $\mathrm{p} 14$ &,- 170 &,- 004 &,- 180 & ,098 & ,322 &,- 119 &, 116 & ,135 \\
\hline $\mathrm{p} 15$ &,- 006 &,- 020 &, 036 &, 142 &, 187 &, 047 &, 042 &,- 456 \\
\hline p16 &, 013 &, 053 & ,083 &,- 064 &, 342 &, 117 &,- 271 &,- 08 \\
\hline p17 & ,070 &,- 029 &, 042 & ,385 &, 061 &,- 046 &,- 012 &,- 052 \\
\hline p18 &, 122 & ,216 &, 148 & ,066 & ,038 &,- 174 &,- 429 & ,182 \\
\hline p19 & ,042 & , 190 &,- 099 & ,027 &,- 015 & ,097 &,- 139 &,- 104 \\
\hline $\mathrm{p} 20$ &, 055 &,- 022 &, 358 &,- 015 &, 001 & ,011 &, 063 &, 001 \\
\hline $\mathrm{p} 21$ & ,262 &,- 084 &,- 006 &, 025 &, 054 &,- 005 &,- 022 &,- 009 \\
\hline $\mathrm{p} 22$ &,- 002 &,- 011 &,- 300 &,- 074 &, 014 &,- 078 &, 151 &,- 020 \\
\hline $\mathrm{p} 23$ & ,256 &,- 011 &,- 026 & ,088 &,- 108 & ,138 &,- 037 &,- 050 \\
\hline p24 &, 322 &,- 058 &, 038 &,- 041 &,- 011 &,- 116 &,- 122 &,- 077 \\
\hline $\mathrm{p} 25$ &, 041 & ,039 &, 340 &,- 008 &,- 003 &,- 050 & ,012 &,- 063 \\
\hline $\mathrm{p} 26$ &,- 014 &,- 036 &,- 044 &,- 025 &,- 111 & ,461 &,- 048 & ,093 \\
\hline $\mathrm{p} 27$ & ,216 &,- 096 &, 004 & ,071 &,- 064 &,- 005 & ,221 & \\
\hline
\end{tabular}

Fonte: Elaborado pelos autores.

Se os itens componentes da matriz varimax apresentarem valores acima de 0,1 quer dizer que esses itens selecionados são satisfatórios para explicar os fatores rotacionados. No estudo em tela apenas 8 fatores seriam o 
suficiente para explicar o comportamento dos estudantes analisados em relação ao comportamento.

A vantagem de utilizar a análise fatorial como ferramenta estatística é que se diminui a quantidade de variáveis sem perder informações importantes, além de medir ou identificar estruturas subjacentes com fatores reduzidos para a análise.

A partir das respostas e dos testes estatísticos aplicados observa-se que os alunos pretendem utilizar as notas explicativas como um mecanismo de descrever as práticas contábeis adotadas pela empresa, seguindo as notas estabelecidas para tanto.

\section{Considerações Finais}

Esta pesquisa teve por objetivo analisar a influência dos traços de personalidade do Dark Triad dos acadêmicos do curso de ciências contábeis na divulgação das informações financeiras apresentadas nas notas explicativas.

Por meio dos resultados encontrados, observa-se que a maioria dos participantes da pesquisa possuem entre 16 a 25 anos e atuam profissionalmente na área contábil. No que tange, ao nível de classificação dos traços de personalidade em relação ao maquiavelismo, narcisismo e psicopatia os investigados possuem traços moderados, e quanto a elaboração das notas explicativas os mesmos evidenciam que pretendem adotar as normas como regra principal para elaboração das mesmas, uma vez, que ao analisar as questões que apresentava características Dark Triad os mesmos discordaram quanto a solução apresentada.

Em geral pode-se inferir que apesar dos participantes apresentarem características moderadas de maquiavelismo, narcisismo e psicopatia, com tendência a ter atitudes que sejam menos desonestas em sua atuação profissional, essa tendência não apresentou influência quanto a qualidade da divulgação das informações financeiras evidenciadas pelas notas explicativas.

Este estudo apresenta limitações em relação à amostra utilizada, por serem acadêmicos de uma única universidade, nesse contexto, sugere-se como futuras pesquisas investigar junto aos acadêmicos de outras universidades possibilitando a comparação entre as mesmas, bem como, aplicar esse estudo junto aos profissionais contábeis com o objetivo de investigar se os mesmos apresentam o mesmo padrão de resultado.

Vale salientar aos pesquisadores que aplicam a técnica da Análise fatorial, que está utiliza como principal fonte para seus cálculos uma matriz de correlação, que se torna frágil a situação de correlação espúria. Nesse sentido a qualidade das informações submetidas durante a fase de análise dos dados deve ser criteriosa, a fim de alcançar um resultado adequado com a análise fatorial. Assim, a maioria das correlações precisa estar acima de 0,30; Bartlett Test Sphericity precisa ter nível de significância menor do que 0,05 e Measure of Sampling Adequacy (MSA) maior do que 0,50 (CORRAR; PAULO; DIAS FILHO, 2007).

Assim, conclui-se que o intervalo de autovalores é que definira a utilização de uma maior ou menor quantidade de fatores que consigam explicar o comportamento dos estudantes. Nessa pesquisa concluímos que apenas 8 fatores têm capacidade de explica mais de $60 \%$ das variáveis adotadas para avaliar o comportamento dos estudantes em relação ao narcisismo, psicopatia e ao maquiavelismo.

\section{Referências}

AVELINO, B. C.; LIMA, G. A. F. A Influência do Narcisismo no Ambiente Acadêmico: Aspectos Relacionados a Desonestidade. In: XIV Congresso USP Controladoria e Contabilidade, 2014, São Paulo. Anais...São Paulo: USP, 2014. p. 1-17.

BLACK, P.J. The Dark Triad and Interpersonal Assessment of Vulnerability: Cues Used and Accuracy. University of British Columbia. Jan, 2013.

BRASIL. Lei n. 6.404, de 15 de dezembro de 1976. Dispõe sobre as Sociedades por Ações. Brasília, 1976. Disponível em: <http:// www.planalto.gov.br/ccivil_03/leis/L6404consol.htm>.

CAMPOS, C.; LEMES, S. Ensino de Notas Explicativas nos Cursos de Ciências Contábeis de Universidades Públicas Brasileiras, Revista de Administração, Contabilidade e Economia, v. 13, n. 1, p.249-282, 2013.

CORRAR, L. J.; PAULO, E.; DIAS FILHO, J. M. Análise Multivariada: para os Cursos de Administração, Ciências Contábeis e Economia. São Paulo: Atlas, 2007.

D'SOUZA, M. F.; LIMA, G. A. S. F. The Dark Side of Power: The Dark Triad in Opportunistic DecisionMaking August 10, 2015. Advances in Scientific and Applied Accounting, São Paulo, v. 8, n. 2, p. 135 - 156 mai./ago. de 2015 . 
D'SOUZA, M. F. Manobras Financeiras e o Dark Triad: o Despertar do Lado Sombrio na Gestão. 2016.199 f. Tese (Doutorado em Controladoria e Contabilidade) - Faculdade de Economia, Administração e Contabilidade, Universidade de São Paulo, São Paulo, 2016.

MARTINS, E.; GELBCKE, E. R.; SANTOS, A.; IUDICIBUS, S. Manual de Contabilidade Societária: Aplicável a todas as Sociedades de Acordo com as Normas Internacionais e do CPC. $1^{\circ}$ ed. São Paulo: Atlas, 2010.

FURNHAM, A.; RICHARDS S. C.; PAUlHUS, D. L. The Dark Triad of Personality: a 10 Year Review. Social and Personality Psychology Compass. v.7, n.3, p. 199-216, 2013.

GROHMANN, M. Z; BATTISTELLA, L. F. Maquiavelismo nas Organizações: o Relacionamento entre Perfil Individual e Personalidade Maquiavélica, Invenio, v.15, n.28, p 101-118, 2012.

JONES, D. N.; PAULHUS, D. L. Introducing the Short Dark Triad (SD3): A Brief Measure of Dark Personality Traits, Assessment, v.21, n.1, p $28-41,2014$.

JONES, D. N.; PAUlHUS, D. L. Machiavellianism. In: M. R. Leary \& R. H. Hoyle (Eds.) Handbook of Individual Differences in Social Behavior. New York: Guilford. 2009.

LOPES, S. S. et al. Dark Triad: Análise do Perfil de Personalidade em Estudantes da Área Contábil. In: II Congresso UnB de Contabilidade e Governança, 2016, Brasília. Anais... Brasília: UnB, 2016. p. 15.

MARTIN, R. A. et al. Relationships Between the Dark Triad and Humor Styles: A Replication and Extension. Personality and Individual Diferences. v.52, n.2, 2012.

MELO JUNIOR, J. S. M., RONCHI, C. C. Liderança e Narcisismo: Indissociabilidade para Interpretação no Ambiente Organizacional. In: XXXVII Encontro da ANPAD, 2013, Rio de Janeiro. Anais... Rio de Janeiro: Anpad, 2013.

PAUlHUS, D. L.; WILliAMS, K. M. The Dark Triad of Personality: Narcissism, Machiavellianism, and Psychopathy. Journal of Research in Personality, v. 36, n. 6, p. 556-563, 2002.

SCHARF, L.; BORGERT, A.; PAES, S. G. A Depreciação e a Capacidade Informativa das Notas Explicativas e Quadros Suplementares. In: VIII Congresso USP Controladoria e Contabilidade, 2008, São Paulo. Anais... São Paulo: USP, 2008.

VRIES, M. FR.; MILLER, D. Narcisismo e Liderança: uma Perspectiva de Relações de Objetos. Revista de Administração de Empresas, v. 30, n. 3, p. 5-16, 1990.

MACCOBY, M. Narcissistic Leaders: The Incredible pros the Inevitable Cons. Harvard Business Review, v. 82, n. 1, p. 92-101, 2004.

BODDY, C. R. Corporate psychopaths: Organizational Destroyers. 2011. Disponível em: $<$ https://historicalunderbelly.files.wordpress.com/2012/12/corporate-psychopaths.pdf $>$.

NATHANSON, C.; PAULHUS, D. L.; WILLIAMS, K. M. Predictors of a Behavioral Measure of Scholastic Cheating: Personality and Competence but not Demographics, Contemporary Educational Psychology. V. 31, n. 1, 2006. 